\title{
Natural Resource Exploration using Marine Controlled-Source Electromagnetic Sounding
}

\author{
Steven Constable \\ Scripps Institution of Oceanography, La Jolla, California
}

\begin{abstract}
Frequency domain electric dipole-dipole controlled-source electromagnetic (CSEM) sounding methods, first developed to study the oceanic lithosphere in the 1980's, have been successfully applied to the exploration of oil, gas, and gas hydrate. In the case of hydrocarbon exploration, several companies have been offering commercial services for several years. However, considerable research remains to be carried out, and the marine EM group at Scripps is active in the development of software, instrumentation, and field techniques for CSEM studies. New instrumentation includes a continuously towed, three-axis electric field receiver, a highly sensitive long-antenna electric field gradiometer, and a novel long baseline acoustic navigation system for accurately locating the deep-towed transmitter. This equipment was used on two recent field campaigns, one to study gas hydrate in the Gulf of Mexico, and one to study a gas field off the Northwest shelf of Australia.
\end{abstract}

\section{INTRODUCTION}

Historically, marine electromagnetic (EM) methods have been employed to study the crust and mantle of the deep ocean, work dating back to Charles ('Chip') Cox's pioneering work on the marine magnetotelluric (MT) method ${ }^{1)}$ and controlled source EM $(\text { or CSEM })^{2)}$. The recent interest in marine EM has been driven in large part by the challenges presented by deepwater exploration and an associated high cost of drilling.

The development of the current generation of marine EM equipment for exploration was first driven by the problem of subsalt exploration in the Gulf of Mexico. Analysis by Hoversten and Unsworth ${ }^{3)}$ suggested that EM methods would be capable of identifying the thickness of salt, and that the MT method would be the tool of choice. The appropriate methodology ${ }^{4}$ and instrumentation ${ }^{5)}$ were developed at Scripps and Berkeley under industry sponsorship. Several marine MT surveys were carried out to tackle the sub-salt problem in the Gulf of Mexico ${ }^{6}$, the carbonate problem offshore Sicily ${ }^{7}$, and the sub-basalt problem offshore Faroes ${ }^{8)}$, all areas where the seismic method runs into difficulty because of large impedance contrasts between lithological units which also present electrical targets. In spite of successes in all three arenas, the method failed to excite initial enthusiasm within the industry.

Around the year 2000 ExxonMobil and Statoil both

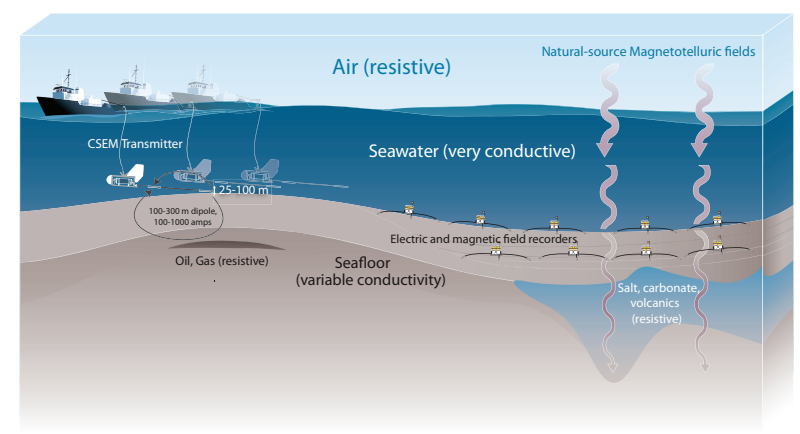

Figure 1. Basic methods used in marine EM. For marine MT (left), seafloor instruments record time series of electric and magnetic fields. The transfer function between $\mathbf{E}$ and $\mathbf{B}$ provides an estimate of seafloor electrical impedance. MT is particularly good at mapping broad geological structure, and is especially sensitive to conductors. For CSEM (right), a deeptowed transmitter broadcasts energy to the same seafloor receivers. CSEM is sensitive to shallower structure than MT, and is especially sensitive to resistors.

started investigating the use of CSEM for direct hydrocarbon detection. Both carried out field trials offshore Angola using an almost identical combination of the UK research vessel the RRV Charles Darwin, a receiver fleet made up of all or mostly SIO marine MT receivers, and the Southampton University EM transmitter called DASI. Statoil pursued this more aggressively, and was the first to carry out a survey and publish the results ${ }^{9)}$. ExxonMobil characteristically were slower to advertise their activities, first going public through the popular press ${ }^{10}$, with a journal article coming much later ${ }^{11)}$. Both companies have put proprietary spin on what is really a public domain 
method, Statoil calling it 'seabed logging' or SBL and ExxonMobil 'remote reservoir resistivity mapping', or R3M.

\section{METHODS}

Figure 1 illustrates the basic methods currently employed in marine EM. Seafloor recorders make timeseries measurements of the electric and magnetic fields at discrete locations. The ionospheric and magnetospheric MT source fields propagate into the sea and a seafloor MT response can be processed from the data much like a land MT impedance.

In the CSEM method, an EM transmitter was deeptowed close to the seafloor in order to replace the high frequency MT signals lost in the overlying, conductive water ${ }^{12)}$. The transmitter is towed close to the seafloor so that the fields couple well to the resistive seafloor rocks. The skin depth in seawater $(270 \mathrm{~m}$ at $1 \mathrm{~Hz}$ ) is shorter than in seafloor rocks, and so at some range from the transmitter the electric and magnetic fields are dominated by energy propagating through the seafloor and not through the seawater. This is opposite to the use of controlled sources on land, where the received signals are dominated by the primary field propagating through the atmosphere, thus encouraging the use of time domain methods in which measurements are made after transmitter shut-off (time domain methods are now being considered for use in shallow water environments).

In the frequency domain CSEM method, the amplitude and phase of the transmitted signals as a function of range, geometry, and frequency are used to recover seafloor conductivity structure. Because there is a vertical component to the electric current flow, especially along the axis of a dipole transmitter, the CSEM method is sensitive to thin resistive layers of sufficient lateral extent, such as hydrocarbon reservoirs, or volcanic sills, evaporite horizons, and so on.

\section{INSTRUMENTATION}

The Scripps ocean-bottom EM (OBEM) receiver (Figure 2) is the result of over 25 years development, starting with the early work on CSEM receivers by Charles Cox and colleagues ${ }^{13)}$. The first version of the broadband MT system is described by Constable et al.5), although the current instrument has been significantly improved since then.

The current version of the logging system has 8 channels of 24-bit digitization with data stored to a compact flash card. All channels are sampled simultaneously at rates between $32 \mathrm{~Hz}$ and 1,000 Hz. Data

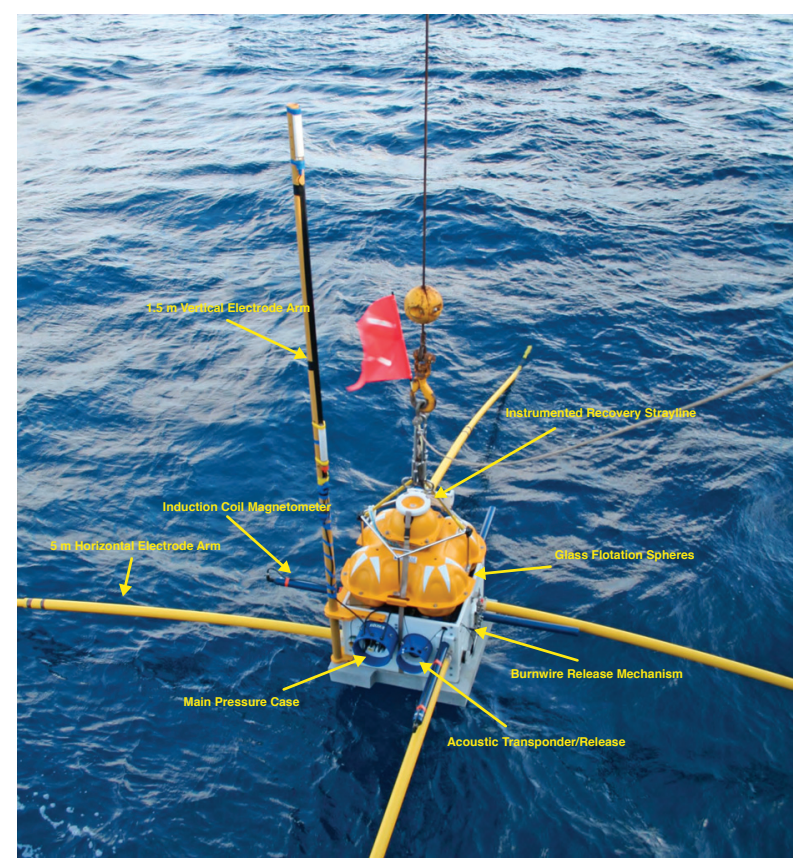

Figure 2. Electric/magnetic field receiver being deployed. Two orthogonal, $2 \mathrm{~m}$ induction coil magnetometers measure field variations between $1 \mathrm{~Hz}$ and $10,000 \mathrm{~s}$. Four $5 \mathrm{~m}$ plastic arms are terminated with silver chloride electrodes to measure electric field variations. The receiver is sunk to the seafloor using a $200 \mathrm{~kg}$ concrete anchor, which is released by acoustic command to allow the instrument to surface under the buoyancy of four oceanographic flotation spheres. The fifth, smaller, sphere contains a GPS receiver, radio modem, and LED strobe light for recovery (aided also by an orange flag).

are buffered in 8 Mbyte of RAM between writing to flash/disk in order to minimize power and noise on the signal channels. Timekeeping is achieved through a low-power oscillator accurate to a couple of milliseconds per day, timed using a GPS standard at the beginning and end of deployment. The logging system and amplifiers are housed in aluminum pressure cases capable of deployment in 6,000 m water depth.

The electric field sensors consist of high gain, chopper amplifiers that are AC coupled to silver-silver chloride electrodes to eliminate self potentials and long period noise. Electrodes are mounted on the ends of $10 \mathrm{~m}$ antennae of polypropylene tubing to provide a noise floor of around $10^{-20}(\mathrm{~V} / \mathrm{m})^{2} / \mathrm{Hz}$ at $1 \mathrm{~Hz}$. The bandwidth of the system is from several hundred herz to about 3,000 seconds.

Magnetic field sensors consist of multi-turn windings around permalloy cores. Aluminum wire is used to dramatically reduce weight over copper windings, at a small cost in resistance noise. The sensors are housed in aluminum pressure cases. Usable bandwidth is between $1 \mathrm{~Hz}$ and 10,000 seconds; the system is sensitive to higher frequencies, but the noise floor makes natural source-field measurements difficult. 
Power is a paramount consideration in seafloor instrumentation that must operate on batteries and also float in water, and this system consumes less than $400 \mathrm{~mW}$, allowing deployments of up to 2 months using lithium primary batteries or rechargeable $\mathrm{NiMH}$.

An acoustic transponder navigation/release system allows the instrument to be tracked in the water and surveyed on the seafloor, as well as allowing the buoyant instrument to be released from the $200 \mathrm{~kg}$ concrete slab used as an anchor. The large anchor is necessary to minimize motional noise in the magnetic sensors. Even so, seafloor tidal currents generate periods during which some deployments cannot collect usable MT data, and so 2-7 day deployments are necessary for full bandwidth MT results.

The entire system is housed in a framework of noncorroding, non-magnetic, neutrally buoyant plastic using a minimum of non-magnetic stainless steel fastenings and framing. We have carried out over 1,000 deployment/recovery cycles with the current version of this system, with a similar number carried out by industry, with an overall loss rate of less than $1 \%$ and a data recovery rate in the high 90's of percent.

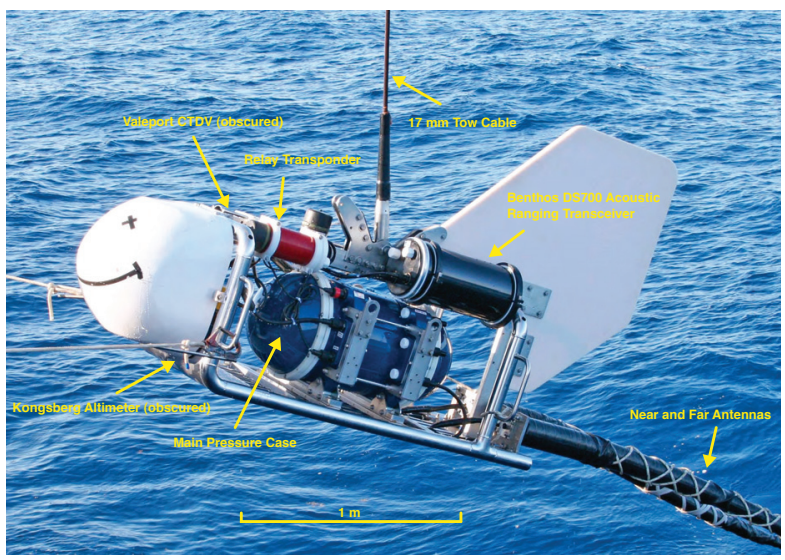

Figure 3. The 500 A Scripps EM transmitter being deployed.

The SIO underwater electromagnetic source instrument (SUESI, Figure 3) is a modern version of the transmitter described in Constable and $\mathrm{Cox}^{14)}$. A 2000 VAC current is transmitted down the towing cable at $400 \mathrm{~Hz}$ to the 'fish', where it is transformed to lower voltage/higher current, rectified, and switched or modulated at the transmitting frequency. A transmission antenna of 100-500 m length, made neutrally buoyant by using an aluminum conductor and thick plastic jacket of density less than water, is towed behind the fish to create a dipole moment given by antenna length times transmission current (up to $500 \mathrm{~A}$ ), typically about $10^{5} \mathrm{Am}$. The $400 \mathrm{~Hz}$ high voltage power is synchronized to a GPS clock, in order to cre- ate a stable transmitter phase which has essentially no drift. Any binary or ternary waveform can be transmitted, and we have experimented with a variety of schemes. Currently we are using a compact binary waveform having nearly two decades of usable frequency content. The SIO transmitter uses 9,600 baud FSK telemetry overlain on the coaxial copper power conductors to collect data from an altimeter, depth gauge, tiltmeter, compass, sound velocity meter, temperature sensors, and current sensors in real time. The transmitter is "flown" at a height of 50-100 m above the seafloor.

Since the electric fields fall off rapidly from the transmitter (inverse cubed from the dipole geometry plus exponential skin-depth attenuation), the transmitter to receiver range and geometry needs to be known as well as possible. Industrial groups use ultrashort baseline (USBL) acoustic systems to locate the transmitter. We have developed a novel long baseline (LBL) system that uses two surface towed LBL transponders located by GPS, and an intelligent acoustic ranging system on the actual transmitter. Ranges to the two transponders along with the depth allows the calculation of the fish position, precise to about $3 \mathrm{~m}$.

For mapping the shallower parts of the crustal section, such as for gas hydrate imaging, many groups tow electric field receivers at fixed offset behind a transmitter. We have developed a neutrally buoyant package to do this behind SUESI (Figure 4), avoiding the hazards of towing either the transmitter or receiver in contact with the seafloor. Our modeling shows that if hydrate fills high-angle faults, a significant vertical electric field will develop, and so we have designed this instrument to measure all three axes of the field.

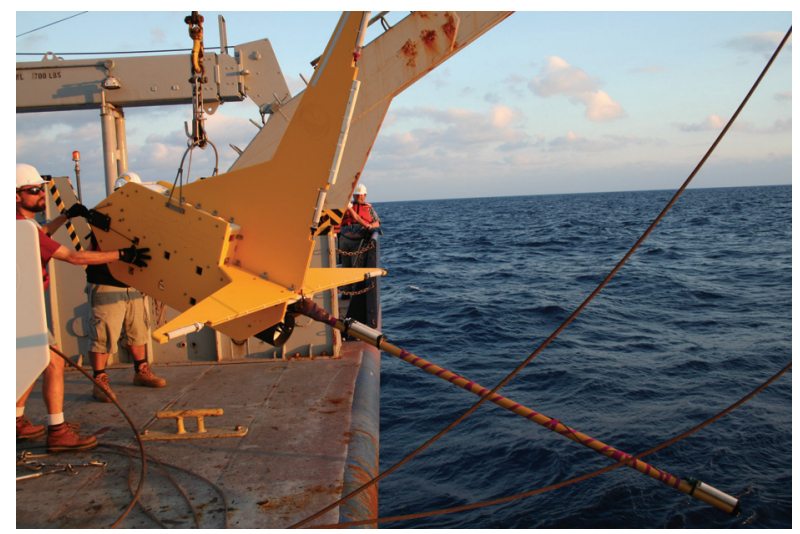

Figure 4. A novel towed, 3-axis electric field recorder designed to be flown at fixed offset behind the transmitter.

For the detection of deep hydrocarbon reservoirs, horizontal electric fields are typically measured at 
source-receiver offsets of about $5 \mathrm{~km}$. Electric field amplitudes are usually larger in the presence of a resistive reservoir, but this effect can be small and confused with other variations in near-surface resistivity, errors in transmitter navigation, etc. However, increased apparent phase velocities are characteristic of deep resistors, and so we have developed a sensitive gradiometer to measure phase gradients with high precision, with accuracies approaching one thousandth of a degree per meter.

\section{RECENT RESULTS}

In October 2008 we carried out surveys over four areas thought or known to host gas hydrate in the Gulf of Mexico. We deployed 30 receivers a total of 94 times and towed the transmitter a total of 103 hours, using a 200 A current on a $50 \mathrm{~m}$ dipole. A 3axis receiver was towed at a constant offset of $300 \mathrm{~m}$. Unfortunately, our new LBL navigation system was not yet operational, and so effort is ongoing to recover transmitter navigation parameters from the structure of the short-offset EM field data. Apparent resistivity pseudosections should be available to show at the meeting.

In May/June 2009 we carried out a 32 day cruise in order to collect marine magnetotelluric (MT) and controlled source electromagnetic (CSEM) data over the Scarborough gas field on the northwest shelf of Australia. The objectives of the experiment were to test new CSEM equipment systems and to provide a comprehensive data set for the study of various modeling and interpretation methods. A total of 54 marine EM recorders were used, which included two long-antenna gradiometers and two towed 3 -axis recorders. Two marine EM transmitters were provided, and which were operated at $300 \mathrm{~A}$ emission current on a $250 \mathrm{~m}$ antenna, for a source dipole moment of $75 \mathrm{kAm}$. The source waveform was our newly designed sequence that provides a fairly dense array of harmonics from the $0.25 \mathrm{~Hz}$ fundamental to at least $10 \mathrm{~Hz}$. The long baseline (LBL) acoustic system was used to track the transmitter during operation, and standard LBL navigation was used to position all the receivers, providing a position accuracy of about $3 \mathrm{~m}$ for both receivers and transmitter. Coupled with compass/tiltmeters mounted on all seafloor instruments, these systems should provide better constraints on the CSEM geometry than normally obtained in commercial surveys.

The project was divided into four phases. The first phase collected data to provide 1D and 2D responses over the structurally simple southern part

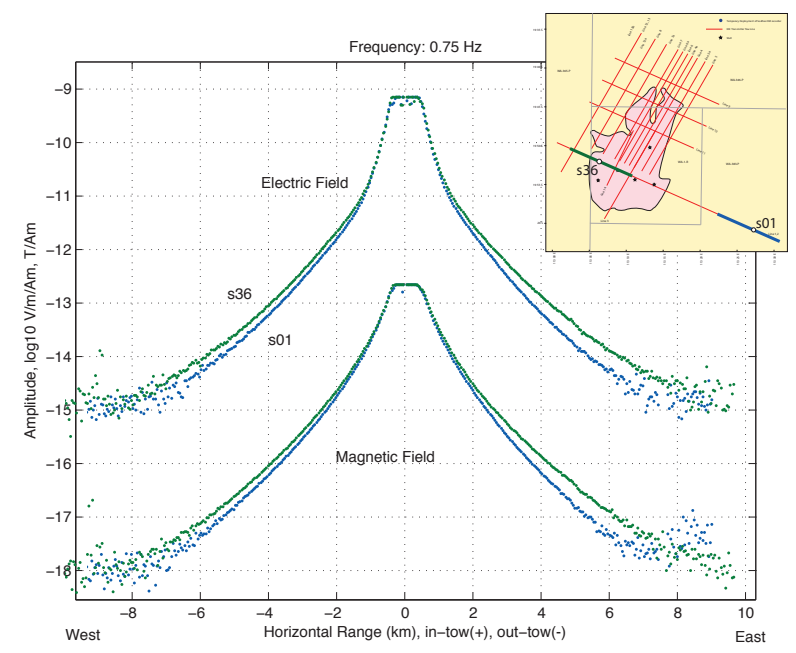

Figure 5. Example data from a recent survey of the Scarborough gas field, off northwestern Australia. The effect of the gas reservoir is clearly seen in elevated electric field and magnetic field amplitudes over the target (green data) compared with off (blue data).

of the gas accumulation, the second collected 3D data over the more structurally-differentiated northern part, the third was targeted at a deeper structure, and the fourth collected data in ways specifically designed to look at shallow resistivity in an area thought to have shallow gas and hydrate. A total of 144 receiver deployments were made, with a total of 12 days CSEM transmitter tow. All receivers were recovered, with data.

Cursory inspection of the data shows that there is a clear CSEM signal associated with the reservoir on both electric and magnetic field channels at sourcereceiver ranges of 1 to $6 \mathrm{~km}$ (Figure 5). Noise floors on the electric field $\left(10^{-15} \mathrm{~V} / \mathrm{Am}^{2}\right)$ and magnetic field $\left(10^{-18} \mathrm{~T} / \mathrm{Am}\right)$ are good, although apparently limited by fields associated with tidal currents, rather than instrument noise. This may limit the quality of the MT data we can process from these records, although the fairly long deployment times should compensate.

ACKNOWLEDGEMENTS: The author wishes to acknowledge the colleagues who have contributed to the work presented here, especially Kerry Key, Karen Weitemeyer, and David Myer. He would also like to thank the technicians and engineers of the Scripps Marine EM Laboratory, particularly Jacques Lemire and John Souders. Funding for this work came from the Scripps Seafloor Electromagnetic Methods Consortium, with additional funding from the US Department of Energy and BHP Billiton. 


\section{REFERENCES}

1) Cox, C.S., J.H. Filloux, D.I. Gough, J.C. Larson, K.A. Poehls, R.P. Von Herzen, and R. Winter, 1980. Atlantic lithosphere sounding. J. Geomag. Geoelect., 32, Suppl. I, SI 13-SI 32.

2) Cox, C.S., 1981. On the electrical conductivity of the oceanic lithosphere. Phys. Earth Planet. Int., 25, 196-201.

3) Hovsersten, G.M., and Unsworth, M., 1994. Subsalt imaging via seaborne electromagnetics. Proc. Offshore Tech. Conf., 26, 231-240.

4) Hoversten, G.M., H.F. Morrison, and S.C. Constable, 1998. Marine magnetotellurics for petroleum exploration, Part II: Numerical analysis of subsalt resolution. Geophysics, 63, 826-840.

5) Constable, S.C., A.S. Orange, G.M. Hoversten, and H.F. Morrison, 1998. Marine magnetellurics for petroleum exploration Part I: A seafloor instrument system. Geophysics, 63, 816-825.

6) Zerilli, A., 1999. Application of marine magnetotelluric to commercial exploration - cases from the Mediterranean and the Gulf of Mexico. Contributed paper at EAGE 61st Conf. and Technical Exhibition, Helsinki, Finland.

7) Oliver, J., S. Davis, and R. Reddig, 1999. Marine MT as a sub-salt reconnaissance tool in the deep-water Gulf of Mexico. Contributed paper at EAGE 61st Conference and Technical Exhibition, Helsinki, Finland.

8) Peace, D., J. Schofield, A. Orange, R. Servodio, R. Lansdell, M. Woodfin, 2002. Marine magnetotelluric exploration helps unravel secrets of the Faroe Islands. Contributed paper at SEG Int'l Exposition and 72nd Annual Meeting, Salt Lake City, Utah.

9) Ellingsrud, S., T. Eidsmo, S. Johansen, M.C. Sinha, L.M. MacGregor, and S. Constable, 2002. Remote sensing of hydrocarbon layers by seabed logging (SBL): Results from a cruise offshore Angola. The Leading Edge, 21, 972-982.

10) Warren, S., 2004. Exxon Mobil bets on new technology in the hunt for oil. The Wall Street Journal, August 17, 1.

11) Constable, S., and L.J. Srnka, 2007. An introduction to marine controlled source electromagnetic methods for hydrocarbon exploration. Geophysics, 72, WA3-WA12.

12) Chave, A.D., Constable, S.C., and Edwards, R.N., 1991. Electrical exploration methods for the seafloor. In "Electromagnetic Methods in Applied Geophysics, Volume 2", ed. M. Nabighian, Soc. Explor. Geophys., Tulsa., pp. 931-966.

13) Webb, S.C., Constable, S.C., Cox, C.S., and Deaton, T.K., 1985. A seafloor electric field instrument. Geomag. Geoelectr., 37, 1115-1129.

14) Constable, S., and C.S. Cox, 1996. Marine con- trolled source electromagnetic sounding 2. The PEGASUS experiment. J. Geophys. Res., 101, 5519-5530. 